\title{
Multidimensional Poverty in Informal Settlements in Windhoek, Namibia, and Orange Farm, South Africa
}

\author{
Peggie Chiwara and Antoinette Lombard
}

The goal of the study was to explore and compare the multidimensional nature of poverty in informal settlements in Windhoek, Namibia, and Orange Farm, South Africa. The study employed a mixed methods research design that used a collective case study and a cross-sectional survey for the qualitative and quantitative study phases. Findings indicate that poverty in informal settlements is a multilayered phenomenon that has interrelated social, economic, and environmental dimensions. What differs across countries is the level of government commitment through constitutional mandates and policies to mitigate the impact of poverty by rendering basic services and implementing housing schemes and anti-poverty programs such as social grants. Political will is key to finding people-centered solutions. Social and environmental justice campaigns that advocate and lobby governments for accountability in implementing national development plans and social welfare policy commitments are needed.

Keywords: informal settlements, mixed methods study, multidimensional poverty, Namibia, South Africa

Namibia and South Africa are two Southern African neighbors that share a similar history of apartheid governance. Although democracy brought political freedom, social and economic freedom has yet to be realized for the vast majority of black communities in these countries as poverty and inequality persist. Spatial inequality in the urban areas in Namibia and South Africa manifests itself in the separation of residential areas according to class and the concentration of the poor in informal settlements (United Nations Human Settlements Programme, 2001). Although informal settlements do not accommodate all of the urban poor,

Peggie Chiwara, PhD, is a research fellow at the University of Pretoria, Pretoria, South Africa. Antoinette Lombard, PhD, is professor in social work and head of the Department of Social Work and Criminology at the University of Pretoria. 
it is in these settlements that it is easiest to see poor people in their highest concentrations (United Nations Human Settlements Programme, 2003).

Out of a population of 57.7 million people, more than 5 million black South Africans live in informal shack dwellings (Umraw, 2018). Likewise, nearly 1 million $(995,000)$ black Namibians out of a population of 2.4 million people live in informal settlements (Nakale, 2018). Informal settlements fall broadly within the category of slums, which in the general sense of the word encompass a wide range of low-income settlements that are characterized by inadequate housing, overcrowding, insecurity of tenure, and a lack of basic services (United Nations Human Settlements Programme, 2003).

The numerical significance of people living in informal settlements means that global aspirations of ending poverty are intricately bound to the prevailing static conditions in these settlements (Turok, Budlender, \& Visagie, 2017). Globally, information on informal settlement communities remains largely inadequate, outdated, or nonexistent, making it difficult to target interventions (United Nations Children's Fund, 2012). This information gap has implications for addressing poverty in all its forms and dimensions and particularly in communities that are left behind, such as informal settlements.

The goal of the article is to explore and compare the multidimensional nature of poverty in informal settlements in Windhoek, Namibia, and Orange Farm in Johannesburg, South Africa. Social, economic, and environmental dimensions of poverty will be emphasized because these are interrelated and associated with poor human and environmental well-being. The comparison between Namibia and South Africa is intended to explore how these dimensions are similar or different in countries with a compatible socioeconomic and political context. The article will begin by outlining the methodology used for the study. Thereafter, poverty in Namibia and South Africa will be contextualized, followed by a discussion of the multidimensional nature of poverty in informal settlements. A discussion of the findings will highlight the similarities and differences in the experience of social, economic, and environmental dimensions of poverty in Namibia and South Africa.

\section{Methodology}

This article is part of a broader empirical study entitled "Environmental and Community Sustainability for Informal Settlement Communities in Namibia and South Africa: A Comparative Social Work Study" (Chiwara, 2019). This study utilized an exploratory mixed methods design that combined qualitative and quantitative research approaches in two sequential study phases. This integration was informed by the observation that a single research approach does not adequately reveal the state of poverty in poor communities (Navarro, 2001). Three categories of study participants - households, children, and practitioners - took part in the study. The latter group consisted of social workers and human settlement, environmental health, and nonprofit-based practitioners. 
The first phase of the study adopted a qualitative research approach and a collective case study design (Creswell \& Poth, 2018). Using non-probability purposive sampling (Teddlie \& Tashakkori, 2009), the qualitative study sampled 91 participants. A quantitative research approach and a cross-sectional survey design (Creswell \& Poth, 2018) were utilized in the second study phase. The quantitative study sampled a different and larger sample of 531 participants using a combination of systematic and total population probability sampling techniques (Strydom, 2011). Drawing in an entirely new sample incorporated fresh perspectives into the study. The study's sample is presented in table 1 .

Qualitative data were collected through one-on-one and focus group interviews and analyzed thematically (Creswell \& Poth, 2018) with the aid of Atlas. ti 8. Using the themes from the qualitative study, three sets of survey questionnaires were formulated and administered to the practitioners, household, and child participants in the quantitative study. Quantitative data were then analyzed using the Statistical Package for Social Sciences (SPSS).

The study area in Namibia was the Tobias Hainyeko constituency, which is one of the poorest and most rapidly growing constituencies in Windhoek; 78 percent of its housing is shack dwellings (Khomas Regional Council, 2015). Orange Farm was the comparative study area. It has the largest informal settlement population in South Africa (Orange Farm Human Rights Advice Centre, 2016). Among other criteria for inclusion, participants had to be willing and available to participate and to have resided in an informal settlement for at least one year. Household participants had to be older than eighteen years and child participants between thirteen and seventeen years. Practitioners had to be rendering social, economic, and environmental interventions to informal settlement communities.

Ethical clearance was granted by the affiliating university. Written informed consent and assent of all participants and permission of the relevant authorities were obtained prior to conducting the study. Participants were assigned pseudonyms consisting of a fictitious name, an abbreviation representing their population category (or a distinct pseudo numeric or alphanumeric number in the case of practitioners), and their country abbreviation (see table 2).

Table 1 Comparative study sample

\begin{tabular}{lccccrr}
\hline Participant & \multicolumn{3}{c}{ Qualitative study } & \multicolumn{3}{c}{ Quantitative study } \\
categories & $\begin{array}{c}\text { Namibia } \\
(n=50)\end{array}$ & $\begin{array}{c}\text { South Africa } \\
(n=41)\end{array}$ & $\begin{array}{c}\text { Total } \\
(n=91)\end{array}$ & $\begin{array}{c}\text { Namibia } \\
(n=276)\end{array}$ & $\begin{array}{c}\text { South Africa } \\
(n=255)\end{array}$ & $\begin{array}{c}\text { Total } \\
(n=531)\end{array}$ \\
\hline Children & 24 & 15 & 39 & 56 & 41 & 97 \\
Households & 9 & 9 & 18 & 192 & 191 & 383 \\
Practitioners & 17 & 17 & 34 & 28 & 23 & 51 \\
Total & 50 & 41 & 91 & 276 & 255 & 531 \\
\end{tabular}


Table 2 Abbreviations used in participants' pseudonyms

\begin{tabular}{ll}
\hline CP & Child participant \\
HP & Household participant \\
SW & Social work practitioner \\
EHP & Environmental health practitioner \\
HSP & Human settlements practitioner \\
PNPO & Nonprofit organization practitioner \\
SA & South Africa \\
Nam & Namibia \\
\hline
\end{tabular}

\section{Contextualization of Poverty in Informal Settlements}

Namibia and South Africa are upper-middle-income countries that feature as the two most unequal countries in the world. This is evidenced by a Gini coefficient of 0.63 in South Africa and 0.59 in Namibia, with a value of 0 representing absolute equality and a value of 1 representing absolute inequality (World Bank, 2017). The contradiction of inequality in the midst of great wealth attests to Sen's (1999) view that development is not synonymous with an increase in income. Rather it entails the removal of poverty and poor economic opportunities and the expansion of the real freedoms that people enjoy. For the poor, inequalities cancel out the benefits of living in a more affluent society. As a household participant in South Africa [Favour, HP(SA)] affirmed, "We are still living in apartheid but we are . . . [experiencing it through] poverty. . . . We don't see democracy . . . we are still living in that apartheid era but they twisted the style."

In 2015, more than half of South Africa's population (55.5\%) lived below the country's upper bound of poverty, 992 South African rands per person per month (Statistics South Africa, 2018). In Namibia, the upper bound of poverty is 520.8 Namibian dollars per person per month, with the Namibian dollar being pegged at a one-to-one equivalence with the South African rand. In 2016, 17.4 percent of Namibia's population lived below this poverty line (National Statistics Agency, 2019). Although the statistics suggest that poverty is less prevalent in Namibia than it is in South Africa, poverty in Namibia remains difficult to quantify as the set national poverty line does not take into account the actual cost of living. Individuals can therefore be living above the poverty line and yet fail to meet their basic monthly needs (H. Jauch as cited in Ngatjiheue, 2019). An income measure of poverty is also inadequate, as "real poverty in terms of capability deprivation may be, in a significant sense, more intense than what appears in the income space" (Sen, 1999, p. 88). At the same time, income is an equally important indicator of poverty considering the highly monetized nature of life in urban settings as described by a social worker in Namibia [SW 1 (Nam)]: "They are dependent on food that they buy from the shops and if you don't have money?"

From a multidimensional conceptualization, poverty is the lack of whatever is necessary for material well-being, including food, housing, land, and other assets (Narayan, 1999). It is a sense of powerlessness, the relative lack of access to public 
services and other sources of official support (Green, 2012). It also encompasses hunger, ill health, unsafe living conditions, social exclusion, and a lack of access to education and employment (United Nations, 1995). These constitute the social and economic dimensions of poverty in informal settlements.

\section{Social and Economic Dimensions of Poverty in Informal Settlements}

Participants in both Namibia and South Africa described poverty as a defining feature of their communities:

Poverty is the leading factor in Orange Farm. [Mango, CP (SA)]

In . . . our community . . . we are still behind and poverty is still here.

[Timothy, HP (Nam)]

The quantitative survey results presented in table 3 show the extent of poverty in households in the sampled informal settlements. As indicated in table 3, more than a tenth $(11.3 \%, 43 / 382)$ of the household participants in the study described their household as not at all poor, which confirms the observation by Ballinger and Wilke (2015) that informal settlements are not homogenous places because people who earn reasonable incomes also live there. The rest $(88.7 \%$, $339 / 382$ ) described their households as poor, very poor, or extremely poor. On a country level, the findings show that the prevalence $(38 \%, 73 / 192)$ of extreme poverty is higher in informal settlements in Namibia than the national prevalence of 10.7 percent (National Statistics Agency, 2019). In South Africa, 21.1 percent (40/190) described their households as extremely poor, and this closely mirrors the national prevalence (25.2\%) of extreme poverty (Statistics South Africa, 2018).

Table 3 Household participants' description of the extent of poverty in their households $(n=382)$

\begin{tabular}{llccc}
\hline Description & $\begin{array}{l}\text { Participant count } \\
\text { and percentage }\end{array}$ & $\begin{array}{c}\text { Namibia } \\
(n=192)\end{array}$ & $\begin{array}{c}\text { Country } \\
\text { South Africa } \\
(n=190)\end{array}$ & $\begin{array}{c}\text { Total } \\
(n=382)\end{array}$ \\
\hline We are extremely poor & Count & 73 & 40 & 113 \\
We are very poor & $\%$ & $38.0 \%$ & $21.1 \%$ & $29.6 \%$ \\
We are poor & Count & 53 & 29 & 82 \\
\multirow{2}{*}{ We are not poor } & Count & $27.6 \%$ & $15.3 \%$ & $21.5 \%$ \\
& $\%$ & 53 & 91 & 144 \\
Total & Count & $27.6 \%$ & $47.9 \%$ & $37.7 \%$ \\
& $\%$ & 13 & 30 & 43 \\
& Count & $6.8 \%$ & $15.8 \%$ & $11.3 \%$ \\
& $\%$ & 192 & 190 & 382 \\
& & $100.0 \%$ & $100.0 \%$ & $100.0 \%$ \\
\hline
\end{tabular}


A Pearson chi-squared test for independence showed a statistically significant $(p=0.001)$ relationship between living in an informal settlement in Namibia and being identified as extremely or very poor.

People living in informal settlements are often stigmatized as criminals or as lazy or uneducated. Stigma reinforces poverty, as it acts as a barrier to employment and other social and economic opportunities, which are already nonexistent in informal settlements:

It becomes a challenge to access information ... [and] opportunities because of the stigmatised labels that are put on the area. [PNPO C1 (SA)]

There is also bias when people are employing potential employees. If they know ... [that you live in an informal settlement] then they already ... disregard you. [EHP 4 (Nam)]

The quantitative study gathered information on how participants' household circumstances have changed after they moved into an informal settlement to establish whether living in informal settlements is associated with better or worse outcomes (see table 4 ).

As shown in table 4, 38.7 percent (74/191) and 15.2 percent (29/191) of household participants in South Africa, respectively, indicated that poverty in their households was somewhat better or much better after they moved into an informal settlement. This is compared to 20.3 percent (39/192) and 8.9 percent (17/192) of household participants in Namibia who, respectively, indicated that poverty in their households was somewhat or much better. Conversely, more participants in Namibia indicated that poverty in their households was somewhat

Table 4 Changes in participants' household circumstances since moving into an informal settlement $(n=383)$

\begin{tabular}{llccc}
\hline Description & $\begin{array}{l}\text { Participant count } \\
\text { and percentage }\end{array}$ & $\begin{array}{c}\text { Namibia } \\
(n=192)\end{array}$ & $\begin{array}{c}\text { Country } \\
\text { South Africa } \\
(n=191)\end{array}$ & $\begin{array}{c}\text { Total } \\
(n=383)\end{array}$ \\
\hline It is now much worse & Count & 74 & 35 & 109 \\
& $\%$ & 38.5 & 18.3 & 28.5 \\
It is somewhat worse & Count & 31 & 24 & 55 \\
& $\%$ & 16.1 & 12.6 & 14.4 \\
It is still the same & Count & 31 & 29 & 60 \\
It is somewhat better & Count & 16.1 & 15.2 & 15.7 \\
& $\%$ & 39 & 74 & 113 \\
It is much better & Count & 20.3 & 38.7 & 29.5 \\
& $\%$ & 17 & 29 & 46 \\
Total & Count & 8.9 & 15.2 & 12.0 \\
& \% & 192 & 191 & 383 \\
& & 100.0 & 100.0 & 100.0 \\
\hline
\end{tabular}


worse $(16.1 \%, 31 / 192)$ or much worse $(38.5 \%, 74 / 192)$. This is compared to 12.6 percent (24/191) and 18.3 percent (35/191) in South Africa who indicated that poverty in their households was somewhat worse or much worse after moving into an informal settlement. The findings were again statistically significant $(p<0.005)$ as evidenced by a probability value of $p=0.000$ on the Pearson chisquared test in SPSS.

These findings suggest that informal settlement communities in Namibia experience poverty on a much greater scale than those in South Africa. Also, moving into an informal settlement is associated with worse outcomes for households in Namibia than for those in South Africa. This difference could be attributed to the fact that South Africa, unlike Namibia, has a constitutional mandate to provide free water, electricity, and sanitation to indigent households, although service delivery in the poorest communities remains a challenge (South African Human Rights Commission, 2014). This mandate is confirmed by a statement by participant EHP 1 (SA): "The city did try to provide them with communal taps. . . . It's available free of charge ... . If it's not available at the communal tap, Joburg water will send trucks with water, then the people will come and get the water." Sustainable access to adequate drinking water in the sampled study area in Windhoek is problematic as it is delivered to informal settlements through a prepaid water card system: "If you cannot [afford to] recharge it, then you know that, that day you will not drink water" [Olivia, HP (Nam)].

To reduce the incidence and intensity of poverty in poor households, Namibia and South Africa implement nationwide state-sponsored social grant programs. However, the study's findings show a low uptake of social grants in the study area in Namibia; an overwhelming majority $(77.6 \%, 149 / 192)$ of household participants and their household members were not social grant beneficiaries. This is compared to fewer household participants in South Africa (34\%, 65/191) who said that they and their household members are not social grant beneficiaries. A possible reason for the low uptake of social grants is a lack of access to national identification documents. This problem can perpetuate to transmit poverty across generations of parents and their children:

We have a lot of those children [who do not have birth certificates]. ... The problem is here, some parents they don't have . . . [identity] documents and then ... their children now they are not getting their birth certificates. [PNPO B2 (Nam)]

The United Nations Children's Fund (2015) attributes the lack of birth certificates among children in Namibia to spatial barriers and cultural norms that discourage applying for birth certificates. However, a lack of access to national identification documents is not unique to Namibia. A participant in South Africa [EHP 2 (SA)] attributed this to spatial and financial barriers: "If you can't afford . . . going to Joburg . . . to do your ID [identity] card it means that you won't have your ID card because you don't have money." The findings also point to the 
environmental dimensions of poverty, which in Navarro's (2001) view are often not included in conventional definitions of poverty.

\section{Environmental Dimensions of Poverty in Informal Settlements}

The urban land and housing markets in Namibia and South Africa follow a neoliberal path that creates inequalities in land and housing access and ownership (Mzileni, 2018; Weber \& Mendelsohn, 2017). This status quo bolsters an alternative and yet unregulated informal settlement housing market that delivers on the housing needs of the urban poor. However, the building practices in this informal housing market are associated with significant environmental damage:

The stripping of the topsoil is part of [their] clearing , , , rechannelling of the flow of water. . . Those activities bring about erosion. . . . That is . . . [what] I am linking to the degradation [in informal settlements]. [HSP 1 (Nam)]

Also, informal settlement communities can be located in environmentally hazardous areas, with significant human and environmental consequences:

This year ... we had a flash flood where . . . lives were lost. . . These people [had] settled in the middle of a river course. . . . They [normally] fill up the area with sand trying to change the river course but . . . it couldn't divert from its original route. [HSP 5 (Nam)]

They . . . live near the wetlands . . . the places where it doesn't even dry. ... They pollute it ... [as well]. [They] . . . are affected by different types of illnesses. It's just a health hazard . . . most of the times . . . you will see them at the clinic. [SW $3(\mathrm{SA})]$

Rogge (2000) argued that poor environmental conditions are exacerbated by the harsh conditions of living in poverty, with the poor being at an even greater risk of experiencing the combined effects of economic and environmental problems.

The commodification of water-an environmental resource-predisposes those who cannot afford it to fetch it from unsafe sources:

In the informal settlements people have access to unsafe water sources . . . because of the water [that] they pay for, people would go in the [communal toilet] cisterns pull up the pipes and get water from there. Or someone comes and washes their hands in the cistern [and] the next person can come and use that water. [EHP 1 (Nam)]

This finding emerged from the study area in Namibia where the local authority allocates water only for communal toilet use. Fetching water from toilet cisterns is not only dehumanizing but it also has major environmental justice implications, 
as evidenced by an ongoing hepatitis E outbreak, confined to informal settlements, which occurred in Windhoek during data collection:

The hepatitis E outbreak . . is water borne. ... With the strain that we are dealing with . . . there are various things that you can look at, unsafe water sources . . . sewage ponds . . . these are all possible reasons and of course the storage of water at individual households also indicated some discrepancies. After doing some sampling ... we found some faeces [in the drinking water]. [EHP 2 (Nam)]

The quantitative study sought to establish the extent to which disease outbreaks are common in the participants' communities. More than two-thirds of household participants in Namibia $(66.7 \%, 128 / 192)$ and almost a quarter of household participants in South Africa $(24.2 \%, 46 / 190)$ reported that disease outbreaks are to a very great extent a common occurrence in their communities. Conversely, a small proportion (of household participants in Namibia 5.2\%, 10/192) and an overwhelming majority in South Africa (63.2\%, 120/190) reported that disease outbreaks are not at all common in their communities. These findings were statistically significant $(p<0.05)$ as evidenced by a score of $p=0.00$ on the Pearson chi-squared test in SPSS. They show that the informal settlement communities in Namibia were disproportionately vulnerable to disease outbreaks that are associated with poor environmental conditions.

The environmental dimensions of poverty in informal settlements are also evidenced by what is commonly referred to in literature as energy poverty, which includes reliance on traditional cooking fuels in poor communities (Njiru \& Letema, 2018). This implies that poor households disproportionately suffer from indoor air pollution and respiratory illnesses:

[Some use] imbaula [coal heaters] . . . in their shacks . . . to warm their homes and ... end up inhaling the [toxic] fumes, and getting sick and probably dying as a result of [carbon monoxide poisoning]. [EHP 2 (SA)]

In terms of development it affects them, you have kids there, they are supposed to study in such stuffy places [where there is indoor air pollution, that] . . lack of oxygen. [EHP 1 (Nam)]

A lack of access to clean forms of energy has significant implications for the health and well-being of poor communities and women in particular, who bear the brunt of respiratory and eye problems that result from indoor air pollution (United Nations Economic and Social Council, 2019). The quantitative study findings show that more than two-thirds of household participants in Namibia $(67.5 \%, 129 / 191)$ and close to a third of those in South Africa $(30.5 \%, 58 / 190)$ agreed that air pollution is a significant environmental challenge in their communities. The findings in South Africa are attributed to the fact that the sampled 
communities had access to electricity, albeit through illegal electricity connections. Energy poverty also affects environmental sustainability:

It has come to the extent that the trees are not even having the appropriate time to grow to full age. ... What is happening is that people are actually chopping trees that are still ... green which definitely shows that the sustainability is not going to last us. [EHP 2 (Nam)]

Informal settlement communities are well aware of the human-made environmental impacts in their communities but feel powerless to change the situation:

Deforestation, yes it's going higher because we use wood to cook meals. .. . We are struggling to survive. It's forcing us to do that. Not everyone can afford paraffin or gas, so that's what leads us to cut down trees . . . to cook, to warm up. . . . No firewood, no eating. [Titus, HP (Nam)]

These findings support Yeld's (1997) view that environmental ethics are often considered irrelevant in poor communities, and conservation concerns are seen as an unnecessary luxury in the never-ending struggle for survival.

\section{Discussion of Findings}

Poverty is a known characteristic of informal settlements. This study affirms that poverty is a multilayered phenomenon that has interrelated social, economic, and environmental dimensions. Informal settlements are associated with stigmatization of residents. A lack of access to national identification documents reinforces poverty and prevents individuals from accessing education and employment opportunities that facilitate social and economic inclusion.

Findings on the extent of poverty show that it is experienced on a more severe scale by communities in Namibia than by those in South Africa. In South Africa, the constitutional mandate to provide free water, electricity, and sanitation to indigent households, albeit with limited available resources, serves as a buffer to extreme hardship. In contrast, poor households in Namibia must buy water, and if they cannot afford it they must access it from unsafe sources, which reinforces their vulnerability to health risks and impinges on their human rights and dignity.

Although Namibia and South Africa implement social grant programs for vulnerable children and adults, the findings indicate that the uptake of social grants in informal settlements remains problematic in Namibia. The South African government regards social grants as a high priority for poverty reduction and has undertaken outreach campaigns post-democracy in 1994 to facilitate access to families who qualify, including assisting children to get birth certificates. Programs that increase the uptake of social grants are important in implementing Namibia's self-declared war on poverty as articulated in the Harambee Prosperity Plan (Republic of Namibia, 2016). 
It is evident from the findings in both countries that all people living in informal settlements cannot be assumed to be poor in terms of income. Key to the social exclusion that is experienced by individuals with above average incomes in informal settlements are capability rather than income deprivations. Through its Reconstruction and Development Program, South Africa has delivered 4.3 million houses and housing subsidies to 20 million low-income earners since 1994 (Republic of South Africa, 2016). However, the demand for low-income housing often exceeds the government's capacity to deliver on housing for all. This reality requires innovative public and private partnerships that make urban areas more inclusive and sustainable. Namibia has yet to implement mass housing schemes as private and public sector developers specifically target middle and upper income households (Weber \& Mendelsohn, 2017).

In view of a lack of access to housing for all, informal settlements represent an informal housing market that is associated with significant risks but a market that poor communities regard as important for their survival. Informal settlement communities are both contributors to and recipients of environmental degradation. When communities settle in ecologically hazardous areas, a seemingly natural disaster such as a flash flood may as well be a human-made environmental disaster. To address their need for shelter and energy, informal settlement communities contribute to environmental degradation and disturb natural ecosystems. They also suffer disproportionately from illnesses that are directly linked to their immediate living environments. Residents of these communities are well aware of the environmental risks associated with living in informal settlements but often feel powerless to change the situation due to their struggle for survival.

\section{Conclusion}

The marginalization that is experienced by informal settlement communities jeopardizes the realization of inclusive and sustainable urban areas. A broader understanding of poverty as encompassing social, economic, and environmental dimensions is integral in addressing it in all its forms and dimensions. It can be concluded that the provision of adequate housing and basic services to informal settlement communities is not in itself a comprehensive solution to poverty. Such a solution requires tackling many other interrelated challenges such as structural inequalities, stigma, learned patterns of living that contribute to environmental degradation, and a lack of access to social and economic opportunities. Social and environmental justice campaigns that advocate and lobby governments for accountability in implementing national development plans and social welfare policy commitments are needed.

\section{References}

Ballinger, B., \& Wilke, A. (2015). Redefining the Ahwahnee principles: Challenges from the favelas of Rio de Janeiro. Journal of the International Society for the Study of Vernacular Settlements, 4, 35-59. 
Chiwara, P. (2019). Environmental and community sustainability for informal settlement communities in Namibia and South Africa: A comparative social work study. (Unpublished doctoral dissertation). University of Pretoria, Pretoria, South Africa.

Creswell, J. W., \& Poth, C. N. (2018). Qualitative inquiry and research design: Choosing among five approaches. London, UK: SAGE.

Green, D. (2012). From poverty to power: How active citizens and effective states can change the world. Warwickshire, UK: Practical Action Publishing \& Oxfam.

Khomas Regional Council. (2015). Khomas regional development profile 2015. Retrieved from https://www.khomasrc.gov.na/documents/20760/78517/ Khomas+Regional+Development+Profile+2015+v8/decb60a0-4fb1483a-b00b-09b0f697a6f2

Mzileni, P. (2018). South Africa: The urban land question-Universities in cities. Retrieved from https://allafrica.com/stories/201804190615.html

Nakale, A. (2018). 40\% of Namibians live in shacks. New Era. Retrieved from https://neweralive.na/posts/40-of-namibians-live-in-shacks

Narayan, D. (1999). Crumbling foundations, conflicting relations: Gender, institutions and poverty. Consultations with the poor. Retrieved from http://documents.worldbank.org/curated/en/317621468147318575/ pdf/453490WPOBOX0334096B01PUBLCI1.pdf

National Statistics Agency. (2019). Sustainable development goals baseline report: Namibia 2019. Retrieved from https://d3rp5jatom3eyn.cloudfront.net/cms/ assets/documents/SDG_Baseline_Report_2019.pdf

Navarro, L. (2001). Exploring the environmental and political dimensions of poverty: The cases of the cities of Mar del Plata and Necochea-Quequén. Environment $\mathcal{E}$ Urbanization, 13, 185-199.

Ngatjiheue, C. (2019, August 2). Severe poverty still haunts Namibians. The Namibian, p. 1.

Njiru, C.W., \& Letema, S. C. (2018). Energy poverty and its implication on standard of living in Kirinyaga, Kenya. Journal of Energy, 2018. doi:10.1155/2018/3196567

Orange Farm Human Rights Advice Centre. (2016). Background. Retrieved from https://www.orangefarmadvicecentre.org.za/about/background

Republic of Namibia. (2016). Harambee prosperity plan 2016/17-2019/20. Retrieved from https://www.gov.na/documents/10181/264466/HPP+ page+70-71.pdf/bc958f46-8f06-4c48-9307-773f242c9338

Republic of South Africa. (2016). Annual report 2015/2016. Department of Human Settlements. Retrieved from http://www.dhs.gov.za/sites/default/ files/annual_reports/AR_15-16_WEB.pdf

Rogge, M. E. (2000). Children, poverty and environmental degradation: Protecting current and future generations. Social Development Issues, 22(2/3), 46-53.

Sen, A. (1999). Development as freedom. New York, NY: Oxford University Press.

South African Human Rights Commission. (2014). Report on the right to access sufficient water and decent sanitation in South Africa: 2014. Retrieved from 
https://www.sahrc.org.za/home/21/files/FINAL\%204th\%20Proof\%20 4\%20March\%20\%20Water\%20\%20Sanitation\%20low\%20res\%20(2).pdf

Statistics South Africa. (2018). Mid-year population estimates 2018 (Statistical release P0302). Retrieved from https://www.statssa.gov.za/publications/ P0302/P03022018.pdf

Strydom, H. (2011). Sampling in the quantitative paradigm. In A. S. De Vos, H. Strydom, C. B. Fouché, \& C. S. L. Delport (Eds.), Research at grassroots for the social sciences and the human services professions (pp. 222-234). Pretoria, South Africa: Van Schaik.

Teddlie, C., \& Tashakkori, A. (2009). Foundations of mixed methods research: Integrating quantitative and qualitative approaches in the social and behavioural sciences. London, UK: SAGE.

Turok, I., Budlender, J., \& Visagie, J. (2017). The role of informal urban settlements in upward mobility (Development policy research unit working paper 201701). Cape Town, South Africa: University of Cape Town.

Umraw, A. (2018, June 14). What the numbers say about SA's "squatter camps." Huffington Post. Retrieved from https://www.huffingtonpost.co.uk/2018/ 06/14/what-the-numbers-say-about-sas-squatter-camps_a_23459035

United Nations. (1995). Copenhagen declaration on social development. Retrieved from http://www.un.org/en/development/desa/population/migration/general assembly/docs/globalcompact/A_CONF.166_9_Declaration.pdf

United Nations Children's Fund. (2012). The state of the world's children 2012: Children in an urban world. Retrieved from https://www.unicef.org/sowc2012

United Nations Children's Fund. (2015). A Namibia fit for children: Birth registration. Retrieved from https://www.unicef.org/namibia/Birth_registration_ fact_sheet_print.pdf

United Nations Economic and Social Council. (2019). Special edition: Progress towards the sustainable development goals. Retrieved from https://undocs. org/E/2019/68

United Nations Human Settlements Programme . (2001). The South African Housing Policy: Operationalizing the right to adequate housing. Retrieved from https:// www.ohchr.org/documents/publications/fs21_rev_1_housing_en.pdf

United Nations Human Settlements Programme. (2003). The challenge of slums global report on human settlements 2003. Retrieved from https://www.un.org/ ruleoflaw/files/Challenge\%20of\%20Slums.pdf

Weber, B., \& Mendelsohn, J. (2017). Informal settlements in Namibia, their nature and growth: Exploring ways to make Namibian urban development more socially just and inclusive. Windhoek, Namibia: Development Workshop Namibia.

World Bank. (2017). GINI index (World Bank estimate). Retrieved from https:// data.worldbank.org/indicator/SI.POV.GINI

Yeld, J. (1997). Caring for the earth South Africa: A guide to sustainable living. Stellenbosch, South Africa: World Wildlife Fund. 